\title{
RECRIAR A TELEVISÃO: em defesa de um padrão de qualidade ${ }^{1}$
}

\author{
Rebuilt television to obtain quality viewing
}

\section{Filomena Antunes Sobral}

Professora do Instituto Politécnico de Viseu e bolsista de Doutoramento da Fundação para a Ciência e a Tecnologia, Viseu - Portugal, e-mail: filomena@esev.ipv.pt

\section{Resumo}

A civilização da imagem caracteriza-se por uma utilização em larga escala dos meios de comunicação de massas e, entre eles, a televisão. Nesse sentido, a tecnologia da imagem televisiva, quando aliada a produtos de qualidade, como produções ficcionais adaptadas da literatura, em especial da literatura canônica, pode contribuir, não só para divulgar a uma vasta audiência manifestações culturais, como também revitalizar a herança literária de um determinado país. Assim, este artigo tem como objectivo propor uma reflexão sobre a importância da ficção televisiva de qualidade, incidindo nos formatos seriados telenovela e minissérie, como formas de veicular valores culturais e identidades nacionais por meio do pequeno ecrã.

Palavras-chave: Televisão. Ficção. Qualidade. Telenovela. Minissérie.

\begin{abstract}
The image civilization distinguishes itself by the use of the mass-media on a large scale, among which we can find television. In this sense, when combined with quality products, such as literary adaptations from canonical authors, television can help spread and revitalize cultural and literary heritage of a specific country to a wide audience. Moreover, television's collaboration with the writings of canonical authors in the context of literary adaptation has presented several examples of quality serials. Therefore, the purpose of this paper is to reflect on the importance of television fiction used in soap opera and mini-series formats in order to express cultural values and national identities by means of the small screen.
\end{abstract}

Keywords: Television. Fiction. Quality. Soap opera. Mini-series.

1 Artigo elaborado com o apoio do Programa Operacional Ciência e Inovação 2010 (POCI 2010), co-financiado pelo Governo Português e pela União Europeia, através do Fundo Europeu para o Desenvolvimento Regional (FEDER), e da Fundação para a Ciência e Tecnologia (FCT); este artigo também tem o apoio da FCT através de uma Bolsa de Doutoramento Individual. 


\section{INTRODUÇÃO}

Vivemos num contexto civilizacional multimidiático no qual a imagem assume uma importância fulcral e se dissemina por uma multiplicidade de novos ecrãs, como o computador ou o telemóvel. Desse modo, as tecnologias do som e da imagem introduziram mudanças na esfera cultural e social, levando a uma transformação não só nas expressões culturais, como na sua apreensão e difusão. No entanto, a verdade é que a imagem televisiva continua a ser a principal via de transmissão de informação, diversão e cultura, com fortes influências nas práticas socioculturais (REBELO, 2008; WOLTON, 2000) ${ }^{2}$. Trata-se, por conseguinte, da expansão da dimensão cultural (JAMESON, 1997) de que a ficção televisiva de qualidade, adaptada a partir da literatura, é um bom exemplo.

No que diz respeito ao gênero ficção televisiva em Portugal, que, segundo Isabel Cunha (2008, p. 10), ocupa o maior tempo de emissão em todos os canais generalistas portugueses e no qual se inclui a adaptação televisiva de textos de escritores canônicos, não tem sido produzida muita investigação. A autora refere que "há poucos trabalhos acadêmicos sobre ficção televisiva" (CUNHA, 2008, p. 7), o que contrasta claramente com a visibilidade que o gênero tem nas grades de programação das televisões generalistas de Portugal (CUNHA, 2008, p. 10). Esses dados são também reforçados pelo Anuário da Comunicação (2006-07), no qual se pode constatar que "é notoriamente significativo o tempo dedicado à ficção nacional" (CARDOSO, 2008 , p. 17) nos quatro canais de sinal aberto existentes em Portugal.

Para além disso, em Portugal, segundo dados da sondagem nacional realizada pela Entidade Reguladora da Comunicação Social (ERC) (REBELO, 2008, p. 84-85), as telenovelas estão entre os programas ficcionais mais vistos pelos portugueses. Já em 2007 se tinha verificado essa preferência das audiências de televisão portuguesas, pois de acordo com informação recolhida com a Marktest $(2009)^{3}$, entre janeiro e abril de 2007, as telenovelas foram o tipo de programa mais consumido pelos espectadores portugueses (MARKTEST, 2007). Também o estudo de Gustavo Cardoso (2007, p. 399), indicando que "as telenovelas têm uma posição central no tipo de programas visionados pelos jovens", reflete o gosto dos mais novos por esse formato televisivo.

Tal como as telenovelas, as séries, gênero mais comum, ou as minisséries, produto menos frequente nos ecrãs televisivos, são as produções ficcionais que os telespectadores portugueses mais apreciam.

Neste sentido, procuramos ao longo deste texto reflectir sobre a possibilidade da tecnologia da imagem televisiva veicular propostas de qualidade a partir de dois formatos televisuais de ficção - a telenovela e a minissérie, que são efectivamente gêneros tipicamente televisivos com elevada expressão nas emissoras generalistas portuguesas (CARDOSO, 2008; CUNHA, 2008; REBELO, 2008), que podem, efectivamente, fornecer "informação de interesse público" (CUNHA, 2008, p. 14) e "narrativas úteis" (MEPHAM, 1990, p. 56-60) que contribuam para aproximar a televisão de um padrão de qualidade e promovam também interações sociais.

\section{SOBRE A TELEVISÃO}

Embora a televisão tenha sido durante muitos anos associada depreciativamente à cultura de massas, no entender de Filipe Pena (2001, p. 2) é fundamental "entender que a distinção entre alta e baixa cultura", com raízes na Escola de Frankfurt, deve ser ultrapassada por uma nova atitude de promoção da participação e da cidadania, pois, na esteira de Umberto Eco (1979), o autor reforça que essa tendência separatista não é útil nem para apocalípticos nem para integrados. Pena (2001, p. 2), fundamentando-se em Eco, defende "uma utilização valorativa dos meios de comunicação de massas" em que o importante é saber como é que a cultura de massas pode veicular valores culturais através dos seus meios de difusão. A mesma fonte,

\footnotetext{
2 Na divulgação da edição de 2009 do relatório anual Um Ano de Televisão no Mundo, Jacques Braun, vice-presidente da Eurodata Tv Worldwide, ONG responsável pela publicação, afirmou que o tempo destinado à televisão segue em ritmo crescente em diversos países (MARKTEST, 2009).

3 A Markest Audimetria é a empresa do grupo Marktest responsável por recolher a informação de audiências de televisão em Portugal.
} 
referindo-se especificamente à televisão, considera que "não considerar os produtos televisivos como manifestação cultural, mais do que um anacronismo, parece uma cegueira intelectual" (PENA, 2001, p. 3). Num sentido idêntido, Kristin Thompson (2003, p. 2), partindo da ideia de que "any medium produces bad art and good art", assume uma posição em que defende que, na televisão, também há exemplos de programas e séries que se podem considerar como "art television", legitimando, assim, a necessidade de se empreenderem estudos no campo televisivo que vão para além do seu impacto social e conteúdo ideológico, para se dedicarem à análise estética de programas televisivos ou de episódios de séries televisivas (THOMPSON, 2003, p. 3).

Por outro lado, com o despontar do século XXI, altura em que o determinismo tecnológico assume maior evidência, a discussão em torno da televisão coloca-se em um outro nível e a grande concorrente dessa mídia parece ser agora a internet. Desse modo, há quem advogue que o futuro da televisão caminha para uma convergência centrada no ego, que deverá "incorporar, forçosamente, as mutações dos códigos genéticos gerados pelas vias produtivas da interactividade digital da contemporaneidade" (LOUREIRO, 2008, p. 328). Lança-se, assim, aquilo que Jacinto Godinho (2000, p. 6) argumenta ser "uma sombra acusadora e deslegitimante sobre o acto passivo associado ao consumo de um texto, de uma imagem, de uma obra de arte", o que para o autor é "um tempo benéfico e essencial para o pensamento se apurar", e a mesma fonte alerta, ainda, para o fato da interatividade poder "camuflar a interpassividade", reduzindo a mente a "um mero agente de reacção a estímulos" (GODINHO, 2000, p. 6). Portanto, a questão em torno da televisão parece entretanto começar a desviar-se de saber se ela é ou não um objeto de estudo com interesse, para se centrar nas funcionalidades interativas que a evolução tecnológica atual desenha. Ou seja, a televisão, que ainda não tinha ultrapassado a conotação de "parente pobre" ("poor cousin", THOMPSON, 2003, p. 1) das outras artes, enfrenta uma nova provação e os críticos discutem se é agora que ela vai "desaparecer" (La fin de la télévision, MISSIKA, 2006). É o que Dominique Wolton (2000, p. 55) considera ser, 50 anos mais tarde, uma "vitória sem legitimidade".

Porém, no entender de Cunha (2008), os objetos da cultura de massas constituem, por si só, um foco de interesse para a investigação, na medida em que aliam duas vertentes bastante importantes: por um lado, a visibilidade social, e por outro, são produtos de grande valor econômico. Concordando com esta tomada de posição, sublinhamos, ainda, a vertente de democratização cultural e um lado estético ainda pouco estudado. Essa posição é sobretudo importante em Portugal onde, segundo dados da sondagem nacional realizada em 2008 pela ERC, a televisão "é o meio de comunicação social mais utilizado pelos residentes em Portugal" (REBELO, 2008, p. 67). Esse fato está em concordância com fontes anteriores que, no conjunto das expectativas para o ambiente audiovisual em Portugal, previam que o consumo da televisão iria aumentar até 2007-2010 (CARDOSO, 2006). Também o estudo E-Generation: os usos dos media pelas crianças e jovens em Portugal (CARDOSO, 2007) vem demonstrar que a televisão continua omnipresente na vida das camadas mais jovens, a par com os novos meios tecnológicos, como o computador, o telefone celular ou o leitor de mp3.

\section{QUALIDADE EM TELEVISÃO}

A discussão em torno de uma televisão de qualidade emergiu de forma mais evidente nos anos 1980, no contexto acadêmico britânico, quando, numa época de forte concorrência entre os canais comerciais de televisão, é publicado o livro M.T.M.: quality television (FEUER et al., 1984). Quality television é, portanto, uma expressão que procura chamar a atenção para o "valor estético", a "força dramatúrgica" e a "penetração crítica" (MACHADO, 2000 , p. 22) de alguns programas de televisão. No entanto, o debate em torno da definição do que é a qualidade em televisão, longe de gerar consensos, originou pontos de vista diversos. Isso porque a argumentação sobre a temática "além de controversa pode ser bastante contraditória” (BORGES, 2008, p. 4) e, para além disso, no entender de Arlindo Machado (2000, p. 24), qualidade é uma palavra que "se presta aos mais diferentes usos e às mais escorregadias intenções".

Desse modo, sobressaem as concepções de Jane Feuer, Kerr e Vahimagi, (1984), Paul Kerr (1990), John Mepham (1990), Geoff Mulgan (1990), Robert Thompson (1997), Arlindo Machado (2000) ou Gabriela Borges (2006) que têm o mérito de 
levantar questões culturais, políticas, tecnológicas, éticas e estéticas acerca do que é a qualidade televisiva. Sendo assim, Borges (2006) fala de qualidade em televisão tendo em conta os custos de produção, os índices de audiências e a capacidade de envolvimento social que o médium pode proporcionar. Para a autora, os parâmetros de qualidade em televisão devem considerar, não só, "as propostas estéticas dos programas e indagar até que ponto são veiculadores de histórias úteis", como também, "os mecanismos de participação sociocultural dos cidadãos” (BORGES, 2006, p. 5). Também Mulgan (1990) apresenta várias acepções nas quais a qualidade televisiva se pode inscrever e, assim, esta pode ter a ver com o domínio técnico, com as preferências das audiências, com o uso inovador da linguagem audiovisual, com a vertente pedagógica, com a apresentação de temas de interesse colectivo e, ao mesmo tempo, com a valorização da diversidade.

Mepham (1990), por seu lado, destaca a preservação do pluralismo cultural e democratização social que uma televisão de qualidade deve promover. Thompson (1997), por seu turno, refere que uma televisão de qualidade tem quality pedigree, ou seja, marcas autorais, apresenta geralmente um elenco de excelência, bem como múltiplos enredos; os seus conteúdos são controversos, mais sérios e complexos e há uma tendência para o realismo, isto é, identificação com personagens e situações. Para além disso, de acordo com Thompson (1997), uma televisão de qualidade enfatisa o criticismo social e cultural e está ligada a um certo valor pedagógico. Por outro lado, deve conseguir ser aclamada, não só, pela audiência em geral, como também pela crítica. Ainda de referir o lado estético inovador, criativo e o encorajamento de consumos activos por parte do público espectador.

Por suavez, Machado (2000) considera quea produção industrial associada à televisão não implica obrigatoriamente falta de inovação ou inibição de expressividade autoral. No entender do autor «uma televisão de qualidade deve ser capaz de equacionar uma variedade muito grande de valores e oferecer propostas que sintetizem o maior número possível de "qualidades"》 (MACHADO, 2000, p. 25).

Sendo assim, programas como Hill Street Blues (NBC/ 1981-87), Twin peaks (ABC/ 199091), The sopranos (HBO/ 1999- 2007) ou Six feet under (HBO/ 2001-2005), entre outros, apostam na criatividade, na estética, numa posição crítica sobre determinadas temáticas e apelam à participação intelectual dos telespectadores, representando aquilo que Machado designa por "vontade de reinventar a televisão" (MACHADO, 2000, p. 24). Thompson (2003) vai mais longe na sua análise e defende que este tipo de programas apresenta algumas características que também podem ser encontrados em filmes de arte, como ambiguidades de enredo, profundidade psicológica e complexidade narrativa. Para ilustrar o seu pensamento, a autora estabelece um paralelo entre a série televisiva Twin Peaks (ABC/ 1990-91) e o filme Blue velvet (1986), ambos de David Lynch, para enfatizar o lado estético e autoral das duas produções. Thompson (2003, p. 2) defende que este tipo de programas simboliza "models of how television should be done" e acrescenta que há outros exemplos de programas que se podem aproximar de "art television" (THOMPSON, 2003, p. 135) como é o caso de The singing detective (BBC/ 1986) ou The royle family (BBC/ 1998-2000).

Porém, convém lembrar, em sintonia com Machado (2000, p. 24), que nem todos os produtos televisivos são como Hill street blues. A verdade é que a constelação televisual, devido à sua especificidade de linguagem e funcionamento, é povoada por uma panóplia de diversos tipos de programas audiovisuais. Deste modo, ainda hoje, o debate acerca da qualidade em televisão não gera posições de unanimidade, já que continua a existir uma certa resistência, por parte de algumas mentes mais tradicionalistas, para "vislumbrar um alcance estético em produtos de massa" (MACHADO, 2000, p. 23), enquanto para outros o lado comercial e a produção industrial "não inviabilizam necessariamente a criação artística".

Importa ainda acrescentar que muita da ficção televisiva de qualidade advém da sua relação estreita com a literatura no âmbito da adaptação literária contribuindo a ficção, desta forma, para a veiculação de importantes referências culturais. Em Portugal, como já vimos, existe um grande consumo de ficção televisiva em série, alguma adaptada da literatura, o que faz com que os telespectadores portugueses integrem no seu saber expoentes culturais, não só internacionais, como Charlotte Brontë (Jane Eyre/ 1847), Jane Austen (Orgulho epreconceito/ 1813) ou Elizabeth Gaskell (Norte e sul/ 1854-55), mas também nacionais, como Camilo Castelo Branco (Amor de Perdição/ 1861), Júlio Dinis (As pupilas do senhor reitor/ 1867) ou Eça de Queirós (Os maias/ 1888), entre outros. 


\section{FICÇÃO TELEVISIVA EM SÉRIE}

Ora, se a televisão também pode oferecer propostas culturais, verificamos que muitos projectos de qualidade se materializam, justamente, através de ficção televisiva em série, que se coaduna não só com a forma de funcionamento do médium, como também com as preferências do público espectador.

Do ponto de vista do funcionamento discursivo da televisão, sabemos que este se caracteriza por uma pluralidade de discursos configurados em géneros que, por sua vez, estão organizados em blocos, cuja estrutura geral compõe a grelha de programação televisiva, isto é, o "fluxo ininterrupto de material audiovisual" (MACHADO, 2000, p. 86). Falar em géneros televisivos é, no fundo, classificar os programas em tipologias que partilham as mesmas convenções (MARSHALL; WERNDLY, 2002). Segundo Cunha (2008, p. 5) o conceito de género em televisão, indo buscar as suas raízes às teorias literárias e aos estudos cinematográficos, "é uma ferramenta importante" na medida em que permite a compreensão pelas audiências dos conteúdos veiculados. Assim, os diversos programas televisivos podem ser classificados em géneros, que, no entanto, devido a uma "crescente hibridação", são cada vez mais difíceis de catalogar (CUNHA, 2008, p. 6).

No que diz respeito à estrutura de cada programa em si, também estes são apresentados em blocos, geralmente interrompidos para compromissos comerciais. Esta forma de funcionamento e organização dos conteúdos audiovisuais incentiva os telespectadores a leituras parceladas que motivam um consumo constante e faseado. Cada programa pode ter uma periodicidade diária, semanal, mensal e prolongar-se na emissão durante meses, anos e "em alguns casos até décadas" (MACHADO, 2000, p. 83).

Deste modo, o acto de recepção de um produto em série é totalmente diferente do consumo de narrativas não seriadas. Com isto queremos significar que, numa série a narrativa é propositadamente organizada em torno de cortes ou pausas, o que permite ao telespectador um espaço de reflexão e maturação (ALLEN, 1995, p. 17). Os seriados televisivos devem ainda contemplar a recapitulação de acções anteriores para que a audiência possa ter uma ideia de continuidade, assim como permitir que novos telespectadores se integrem como público receptor da série.
Para além disso, as narrativas televisivas em série podem-se caracterizar por serem narrativas abertas ou fechadas. No que diz respeito às narrativas seriadas abertas, não há um momento final previamente estabelecido, podendo as histórias prolongarem-se durante anos, como é o caso de muitas soap operas e séries norte-americanas. No caso das telenovelas brasileiras e portuguesas, estas também constituem obras abertas na medida em que ainda estão em processo de gestação aquando da sua exibição (HAMBURGER, 2005). Ou seja, a dinâmica de fabricação própria das telenovelas permite que estas sejam passíveis de mudanças e alterações em função de estudos de recepção e em função de estratégias comerciais do canal emissor. No entanto, apesar das telenovelas, tanto portuguesas como brasileiras, revelarem uma orgânica aberta, a verdade é que a extensão das narrativas brasileiras e portuguesas é muito mais curta que o formato norteamericano, tendo as produções lusófonas um final previsto antecipadamente que se atinge ao fim de alguns meses, ou após cerca de duzentos episódios. No que concerne às séries fechadas, categoria na qual se inserem as minisséries, estas são concebidas para terem um final estruturalmente determinado, daíque a narrativa tende a desenrolar-se rumo a um fim previamente estabelecido, embora esse momento final só seja atingido ao fim de vários episódios, geralmente não mais de vinte capítulos, embora actualmente se verifique que algumas minisséries são mais extensas. No entanto, quando as séries fechadas são emitidas o seu texto já está concluído e é menos permeável a interacções exteriores.

Assim, tendo noção da multiplicidade de géneros proporcionada pelo sistema televisivo e que a transposição de um meio escrito para o meio televisual se pode materializar em diversos formatos, importa clarificar que a nossa atenção se foca, de seguida, em dois tipos específicos de narrativas ficcionais televisivas: a telenovela e a minissérie. Esta circunscrição de interesse é motivada porque existe um défice de produção académica sobre o género ficção televisiva em Portugal (CUNHA, 2008, p. 7), porque a ficção ocupa a maior parte da programação televisiva portuguesa (CUNHA, 2008, p. 10) e ainda, porque, para além disso, na preferência dos telespectadores portugueses as telenovelas e séries assumem uma posição central (CARDOSO, 2007, p. 399; REBELO et al., 2008 , p. 85) e constituem, também, um importante testemunho da identidade cultural nacional. 


\section{A IMPORTÂNCIA DOS GÉNEROS TELENOVELA E MINISSÉRIE}

Dominique Pasquier (2006), num interessante artigo sobre os media e a sociabilidade, refere que diversos estudos sobre as ligações entre práticas mediáticas e modos de sociabilidade revelam que a televisão proporciona interacções, não só familiares, como sociais, isto porque, segundo o autor, "A televisão é uma máquina de produção de colectivo" (PASQUIER, 2006, p. 40). Daí que, nos termos de Pasquier (2006), a televisão é um poderoso suporte de trocas interpessoais, o que equivale a dizer, de acordo com este autor, que o ser humano telespectador ao falar de televisão, através dos géneros ficcionais que consome, está, ao mesmo tempo, a revelar elementos sobre si mesmo e sobre o seu lugar no espaço social.

Assim, fixando a temática na ficção seriada portuguesa telenovelas e minisséries, podemos perceber que, nos anos mais recentes, no alinhamento das grelhas generalistas de oferta de programas, começa a verificar-se a inclusão de produtos de qualidade nacionais, baseadas em diversos autores, nomeadamente nos escritores clássicos. É o caso da minissérie Nome de código: sintra (Cunha; Benis; Rodrigues, realização: Jorge Paixão da Costa, RTP1/ 2007) baseada em O mistério da estrada de sintra (Eça de Queirós e Ramalho Ortigão, 1871), João semana (autoria: Francisco Moita Flores, realização: João Cayatte, RTP1/ 2005), minissérie com base em As pupilas do senhor reitor (Júlio Dinis, 1867) ou Quando os lobos uivam (autoria: Francisco Moita Flores, realização: João Cayatte, RTP1 / 2006), minissérie escrita a partir do livro homónimo (1958) de Aquilino Ribeiro. No que diz respeito às sinergias entre autores canónicos e o formato telenovela, merece destaque a adaptação televisiva de dois romances de Camilo Castelo Branco, O retrato de ricardina (1868) e A brasileira de prazins (1882) para a primeira telenovela portuguesa de época, Ricardina e Marta (autoria: Manuel Arouca, realização: Victor Manuel, RTP1/ 1989) ou a adaptação de quatro importantes obras de Eça de Queirós, nomeadamente, $O$ crime do padre Amaro (1875), Os maias (1888), Uma campanha alegre (1890) e O conde de abranhos (1925, póstumo) para a telenovela Lusitana paixão (autoria: Francisco Moita Flores, realização: Jorge Paixão da Costa e André Cerqueira, RTP1/ 2003). Acreditamos que estes produtos audiovisuais, para além de veicularem a cultura e a identidade portuguesa, aproximam os telespectadores dos títulos e conteúdos dos textos que estiveram na base das adaptações. As personagens Simão Botelho e Teresa de Albuquerque do romance Amor de perdição (1962) de Camilo Castelo Branco, por exemplo, são agora conhecidas, também, por alguns telespectadores que nunca tiveram contacto com o texto escrito, o mesmo se passando com Carlos e Maria Eduarda da telenovela Lusitana paixão (Moita Flores/ Jorge Paixão da Costa e André Cerqueira, RTP1/ 2003), que remetem para as personagens principais de $O s$ maias (1888) de Eça de Queirós. Eis um exemplo de que a televisão também pode ser usada para veicular propostas culturais - um retomar da cultura dita erudita mas num meio de massas. A este propósito o director de programas da RTP2, Jorge Wemans (apud CARDOSO, 2009, p. 12), salienta que éimportante propor aos portugueses uma programação que represente "um reencontro, com qualidade, com a produção televisiva que lhes fale das suas raízes culturais e das suas obras".

Prefigura-se, por conseguinte, que sendo produtos típicos da ficção televisiva com alcance sobre um público diversificado, a telenovela e a minissérie exercem fortes influências sociais e culturais, proporcionando, também, a partilha de conhecimentos. Por outro lado, este tipo de ficção reflecte igualmente a identidade cultural de um determinado povo e os valores vigentes numa certa sociedade. São, por conseguinte, peças ideais para pensar a história e a própria dinâmica cultural das comunidades, pois através da sua análise é possível elaborar um retrato social (LOPES, 1995).

No fundo, o que nos parece importante fazer prevalecer é que estamos a falar da representação da sociedade no meio televisão ou da capacidade estética de relembrar, actualizar ou problematizar questões vigentes no social, sempre com uma componente indispensável de fantasia. Ao mesmo tempo está-se também a construir um saber cultural partilhado por toda uma massa anónima de telespectadores que consome a mesma produção audiovisual. Daí Pasquier (2006, p. 41) afirmar que a experiência social da televisão implica a organização de uma "experiência comum".

Para além disso, a telenovela e a minissérie ao colaborarem de uma forma estreita com a literatura proporcionam, a um elevando número de pessoas, uma experiência colectiva de partilha de um repertório audiovisual, e remetem, ao mesmo tempo, para a herança literária, podendo, desta 
forma, estimular o enriquecimento cultural do público telespectador.

Deste modo, a adaptação de obras literárias para televisão, bem como a evocação de episódios marcantes do histórico-social, enfatizam uma determinada representação sociocultural que proporciona identificação e criação de um universo simbólico. Daí que se estabelece uma espécie de espaço público electrónico com o qual os indivíduos e grupos se identificam "e isto acentua os modos de intersubjectividade e sociabilidade" (PAIVA, 2007, p. 2). Assim, a ficção seriada televisiva no formato de telenovela ou minissérie contribui para a construção de um imaginário social colectivo a partir de referências históricas, artísticas, sociais, culturais, económicas e até políticas. Para além disso, ao circularem internacionalmente, estes géneros ficcionais oferecem, também, a possibilidade de "interculturalidade", ou nos termos de Cláudio Paiva (2007, p. 6), o contacto com outras identidades culturais, o que se revela uma troca profícua, em termos de aprendizagens paralelas ou sub-reptícias. É o caso, por exemplo, das representações televisivas ficcionadas de obras de escritores canónicos portugueses.

Com efeito, o contacto com este tipo de representação televisiva permite tornar presente e actualizar através de uma narrativa imagética aspectos históricos, sociais e culturais do povo português que promovem a disseminação de umaidentidade cultural particular. Ou seja, simbolicamente vêem-se representados elementos da cultura portuguesa, como a língua, a gastronomia, a arquitectura, hábitos e modos de ser (pessimismo, saudade), aspectos políticos e religiosos ou referências históricas, que são necessariamente distintos de outra manifestação cultural. $\mathrm{Na}$ verdade, ao vermos representados na televisão usos e costumes, padrões de comportamento, formas de falar e até o vestuário, identificamos se se trata de um produto da cultura portuguesa, americana ou brasileira, por exemplo.

Assim, numa época marcada pela globalização, julgamos que a produção de bens culturais portugueses, como é o caso das adaptações de textos de escritores clássicos para televisão, no formato telenovela ou minissérie, para além de representar um estímulo para acompanhar, de forma mais atenta, as manifestações culturais portuguesas, é também um importante meio de afirmação da identidade nacional através da televisão e testemunha, igualmente, um dos papéis essenciais do médium.
Neste sentido, com vista a finalizarmos o tópico sobre os formatos em série e, adoptando o ponto de vista de Roger Hagedorn (1995), podemos dizer que actualmente as narrativas ficcionais seriadas, sejam no formato telenovela ou minissérie, estão omnipresentes no universo televisivo. Estes são, na verdade, produtos especificamente televisivos que se têm conseguido manter e actualizar, apresentandose, ainda hoje, como formatos integrantes do sistema televisual. Aliás, na acepção de Thompson (2003), a representação em série, de que as telenovelas e as minisséries são dois modelos, caracteriza e distingue claramente o funcionamento do médium televisão e permite estratégias narrativas bastante complexas, que ocultas sob a aparente simplicidade, ou "hidden Complexity" (THOMPSON, 2003, p. 72), permitem sustentar um conjunto de programas fragmentados em episódios por um determinado período de tempo.

Essencialmente e, em termos comparativos, percebemos que a telenovela se diferencia por estar associada a um género menor, enquanto a minissérie é conotada como ficção de qualidade. Contudo, apesar da telenovela e da minissérie terem características distintivas, a verdade é que os dois formatos têm em comum, para além da serialidade, a matriz literária como base de sustentação inicial dos seus conteúdos e que ainda hoje marca presença em algumas produções televisivas.

Ainda assim, estejamos no âmbito das telenovelas ou das minisséries, parece-nos que o essencial é reforçar a ideia, defendida por João Lopes (1995), de que a identidade de uma comunidade, de um povo ou de um país se define "entre muitas outras coisas, pelos modelos de ficção, e em especial, pelos modelos dominantes de ficção, que consome" (LOPES, 1995, p. 13),

Neste sentido, parece-nos interessante observar, que sendo a televisão uma mistura da dimensão técnica, social e cultural, a sua força reside exactamente na capacidade de reafirmação de uma determinada identidade cultural na era do mundo sem fronteiras (WOLTON, 2000, p. 69). Esta é, justamente, para Wolton (2000) a característica distintiva da televisão, a par de ser simultaneamente uma actividade individual e colectiva. Ou seja, a televisão tem a capacidade de remeter a produção televisiva de cada país para uma ambiência histórica, cultural e tradicional que a caracteriza e permite, ao mesmo tempo, preservar identidades. 


\section{CONSIDERAÇÕES FINAIS}

Se é verdade que a televisão não é uma sétima arte como o cinema, sendo acima de tudo um meio de comunicação de massas, não deixa, no entanto, de poder contribuir para a formação cultural dos indivíduos ao reproduzir e transmitir muitas formas de arte.

Efectivamente, a atmosfera íntima em que a televisão é recebida, torna-a num potencial meio privilegiado de disseminação de conteúdos, tal como outrora a rádio foi considerada por André Bazin (2000, p. 23) uma "omnipresença" com potencial para criar uma determinada ambiência cultural. Apesar de se tratar de uma forma de contacto mediada com a cultura, poderá, ainda assim, ser a única forma de contacto para muitas pessoas, pois, como reconheceu Bazin (2000, p. 23), "Don Quixote and Gargantua dwell in the consciousness of millions of people who have never had any direct or complete contact with the Works of Cervantes and Rabelais".

Portanto, não devemos ignorar que a cultura tem o seu lugar nas grelhas televisivas, sendo esta, para Wolton (1994, p. 77), uma das razões do sucesso do médium, "Esquece-se vezes demais que a televisão foi e continua a ser um instrumento de promoção cultural e que se deve ver nisso uma das razões permanentes do seu êxito". Também Eco (1979, p. 351) considera que "a TV pode oferecer efectivas possibilidades de 'cultura". Aliás, para Wolton (2000) a televisão tem a difícil tarefa de promover o acesso à cultura, ao mesmo tempo que proporciona divertimento. Para o autor estas duas dimensões não são incompatíveis, sendo sua convicção de que é possível aliar "espectáculo e cultura, divertimento e qualidade" (WOLTON, 2000, p. 57).

Por outro lado, é significativo notar que também há, em algumas produções televisivas, um "lado estético e divulgador" (BULGER, 2004, p. 17), que não deveria ser diminuído.

Na linha desta constatação, Steven Johnson, num estudo de 2006, reconhece que a cultura de massas também pode oferecer desafios interessantes a nível intelectual. Neste sentido, é significativo notar, de acordo com Johnson (2006, p. 89), que "a tendência crescente de complexidade tem feito melhorar a programação tanto na parte inferior do espectro da qualidade como na parte superior". Do mesmo modo, Thompson (2003) argumenta que desde os anos oitenta do século XX tem-se verificado um acréscimo de complexidade nas narrativas televisivas. Instaura-se então, segundo Johnson (2006), uma nova forma de olhar para os média, já não como unicamente "dopantes", mas como instrumentos que permitem exercitar a mente, ainda que de uma maneira quase "imperceptível" (JOHNSON, 2006, p. 11). Também Jorge Campos (1994) defende um ponto de vista semelhante, salientando o papel activo da mente do espectador numa "atitude crítica e criativa” (CAMPOS, 1994, p. 75). Num sentido idêntido, Wolton (2000, p. 56) defende que "o público é dotado de inteligência crítica".

Deste modo, sobressaem as perspectivas dos optimistas (CAMPOS, 1994; WOLTON, 2000; JOHNSON, 2006) que acreditam na inteligência e capacidade humana para superar os constrangimentos da presença massificadora da caixa televisiva. Numa linha de raciocínio contígua, Eco (1979, p. 353) observou que "a civilização democrática salvar-se-á unicamente se da linguagem da imagem se fizer um estímulo à reflexão crítica e não um convite à hipnose" e a verdade é que o audiovisual já deu provas de que é possível apresentar produtos de qualidade.

\section{REFERÊNCIAS}

ALLEN, R. (Ed.). To be Continued...: Soap Operas Around the World. Nova Iorque: Routledge, 1995.

BAZIN, A. Adaptation, or the cinema as digest. In: NAREMORE, J. Film adaptation. New Jersey: Rutgers University Press, 2000. p. 19-27.

BORGES, G. A discussão do conceito de qualidade no contexto televisual britânico. 2008. Disponivel em: $<$ http://www.bocc.ubi.pt/pag/borges-gabriela-discussao-contexto-qualidade.pdf>. Acesso em: 11 jan. 2009.

Televisão e cidadania: a participação da sociedade civil na 2: portuguesa. 2006. Disponível em: $<$ http://www.bocc.ubi.pt/pag/borges-gabriela-televisao-e-cidadania.pdf $>$. Acesso em: 11 jan. 2009.

BULGER, L. F. A imagem da escrita no pequeno ecrã. Coimbra: Minerva, 2004.

CAMPOS, J. A caixa negra. Porto: Edições da Universidade Fernando Pessoa, 1994.

CARDOSO, G. (Coord.). E-Generation. Lisboa: CIESISCTE, 2007. 
. (Coord.). Anuário da comunicação 2006-2007.

Lisboa: Obercom, 2008.

CARDOSO, J. A. Histórias de Grandes Livros. Jornal Público: P2. 27 Março 2009, p. 12.

CARDOSO, L. (Coord.). Portugal audiovisual. Lisboa: Obercom, 2006.

CUNHA, I. F. Ficção televisiva e entretenimento. In: CONGRESSO BRASILEIRO DE CIÊNCIAS DA COMUNICAÇÃO, 31., 2008, Natal. Anais... São Paulo: Intercom, 2008. CD-ROM.

ECO, U. Apocalípticos e integrados. São Paulo: Perspectiva, 1979.

FEUER, J.; KERR, P.; VAHIMAGI, T. (Ed.). M.T.M.: quality television. Londres: British Film Institute, 1984.

GODINHO, J. Podem as caixas mudar o mundo? Reportagem/ensaio sobre a televisão interactiva. Revista INTERACT, n. 1, Dezembro de 2000. Disponível em: $<$ http://www.interact.com.pt/interact1/flash/actual/ act_2.html>. Acesso em: 10 fev. 2009. p. 1-11.

HAMBURGER, E. O Brasil antenado. Rio de Janeiro: Zahar, 2005.

HAGEDORN, R. Doubtless to be continued: a brief history of serial narrative. In: ALLEN, R. (Ed.). To be Continued...: Soap Operas Around the World. Nova Iorque: Routledge, 1995. p. 27-48.

JAMESON, F. Pós-Modernismo. São Paulo:Ática, 1997.

JOHNSON, S. Tudo o que é mau faz bem. Lisboa: ASA Editores, 2006.

KERR, P. Never Mind the Quality. In: MULGAN, G. The question of quality. Londres: British Film Institute, 1990.

LOPES, J. Teleditadura. Lisboa: Livros Quetzal, 1995.

LOUREIRO, L. M. Convergência e hipermodernidade. Revista Prisma. Com., Porto, n. 7, p. 315-338, 2008.

MACHADO, A. A televisão levada a sério. São Paulo: Senac, 2000.

MARKTEST. Telenovelas captam mais de um quinto do consumo de TV. 2007. Disponível em: <http:// www.marktest.com/wap/a/n/id $\sim$ df4.aspx $>$. Acesso em: 15 mar. 2009.

Um ano de televisão no mundo. 2009. Disponível em: < http:/ / www.marktest.com/wap/a/n/ id 12e8.aspx>. Acesso em: 21 jul. 2009.
MARSHALL, J.; WERNDLY, A. The language of television. Londres: Routledge, 2002.

MEPHAM,J. The ethics of quality. In: MULGAN, G. The question of quality. Londres: British Film Institute, 1990.

MISSIKA, J-L. La fin de la television. Paris: Seuil, 2006.

MULGAN, G. The question of quality.Londres: British Film Institute, 1990.

PAIVA, C. Raça, história e actualidade na ficção de "Escrava Isaura". Revista Conceitos, n. 4, p. 5-8, 2000. Disponível em: <http://www.adufpb.org.br/publica/ conceitos/04/art_01.pdf>. Acesso em: 26 out. 2007.

As minisséries brasileiras. In: COLÓQUIO BRASIL-CHILEDECIÊNCIASDACOMUNICAÇÃO, 1., 2007, Santiago do Chile. Anais... Santiago do Chile: Faculdade de Comunicação da Pontifícia Universidade Católica do Chile, 2007.

PASQUIER, D. Públicos e comunidades sociais. In: ABRANTES,J. C. (Coord.). Ecrãs em mudança. Lisboa: Livros Horizonte, 2006, p. 39-49.

PENA, F. Estética, pluralidade e cidadania nas tevês universitárias. 2001. Disponível em: <http:/ / bocc.ubi. $\mathrm{pt} / \mathrm{pag} / \mathrm{pena}$-felipe-tv-universitaria.pdf $>$. Acesso em: 11 jul. 2009. p. 1-8.

REBELO, J. (Coord.). Os públicos dos meios de comunicação social portugueses. Lisboa: ERC, 2008.

THOMPSON, K. Storytelling in film and television. Harvard: Harvard University Press, 2003.

THOMPSON, R. J. Television's second golden age. New York: Syracuse University Press, 1997.

WOLTON, D. Elogio do grande público. Porto: Edições Asa, 1994.

E depois da Internet? Lisboa: Difel, 2000.
Recebido: 28/08/2009

Received: 08/28/2009

Aprovado: 31/08/2009

Approved: 08/31/2009

Revisado: 08/01/2010

Reviewed: 01/08/2010 